\title{
Does the Coach Leadership Behavior Mediates the Influence of Factors Affecting Coach Leadership Behavioral Styles on Team Success
}

\author{
H. P. N. Perera \\ Department of Sports Science, University of Sri Jayewardenepura, Sri Lanka
}

Received July 29, 2019; Revised August 27, 2019; Accepted September 14, 2019

Copyright $(2019$ by authors, all rights reserved. Authors agree that this article remains permanently open access under the terms of the Creative Commons Attribution License 4.0 International License

\begin{abstract}
The intension of this study is to conclude whether coach leadership behavior serves as a mediator amongst factors affecting said leader behavior and team success in sports. The sample for this was obtained from one hundred and sixty $(n=160)$ athletes who participated in inter university games with special reference to Western Province Sri Lankan. Only team sports are considered and players from individual events are not considered under the current study. Coach leadership behavior was assessed through Revised Leadership Scale for Sports questionnaire (RLSS) and adopted questionnaires were utilized to measure the factors affecting it and the team success. General Linear model and Multiple Linear Regression were the methods used to analyze data. Validity and reliability of the questionnaires were measured through Correlation matrixes and Cronbach's alpha respectively. The results from the study confirm that coach leadership behavior acts as a mediator of the relationship between and factors affecting coach leadership style and team success signifying that factors affecting coach leader behavior may enhance coach behavior in the task of successful performance. Mediating effect was first tested through calculating path coefficients and further conducted the Sobel's test to validate the previous results.
\end{abstract}

Keywords Coach Leadership Behaviour, Mediator Sports, Team Success

\section{Introduction}

A Sport is generally described as an organized, a competitive and a skillful physical activity which entails devotion and fair play. Sports contribute towards cultivation of national peace and harmony. Therefore the United Nations had recognized sports as an important phenomenon in achieving their millennium goals (UN Inter-Agency task Force on Sports for Development and Peace, 2005). International Olympic Committee had also documented that sport can help in bridging cultural and ethnic divides, create jobs and businesses, promote tolerance and non-discrimination (International olympic Committee, 2009).

Therefore there arises a necessity to study and address the issues persist with sports by any nation.

The success records in Olympic and other international sports events especially in team sports are not at all appealing with regard to Sri Lanka (Perera \& Pushpakumari, 2016; Biyanwila \& Perera, 2018). There are many factors that are affecting to the success of sports. Therefore there arises a necessity to study the factors that influence the team success in sports. Hence this study focused to assesses the impact of coach leadership behavior on team success in sports. Among the objectives of the study the core objective is to ascertain the relationship between Coach leadership behavior and team success and the sub objectives were to assess the impact of factors affecting to coach leadership behavior on coach leadership behavioral styles and to measure whether coach leadership styles mediate the relationship between factors affecting to it and team success.

\section{Literature Review}

Factors Affecting Coach Leadership Behavior (FACLB) comprises of three facets (Smoll \& Smith, 1989), namely situational characteristics, leader (coach) characteristics, and team member characteristics. The factors were derived from the multidimensional model of Leadership developed by Chelladurai and Saleh in 1980 .

Situational characteristics are the factors that are beyond the control of the coach and the athletes/team players. A 
model developed by Smoll and Smith (1984) identified factors such as level of competition, nature of the sport, and previous track records of success as situational factors that influence on coach behavior styles. Leader characteristics are the factors inherited with the coach and includes, age of the coach (Chelladurai \& Carron, 1983; Smoll \& Smith, 1989), gender (Rintaugu, Bailasha, \& Toriola, 2011; Smoll $\&$ Smith, 1989), and the explanation of tactics and the trust he has on his own skills (Smoll \& Smith, 1989; Rotter, 1966). Team member characteristics that influences on coach leadership styles includes age of the player (Smoll \& Smith, 1989), gender of the player (Chelladurai \& Arnott, 1985 ; Terry \& Howe, 1984) and the nature of the sport that the players are involve in (Chelladurai \& Saleh, 1980; Terry, 1984; Terry \& Howe, 1984). Nationality and culture from which athletes/team players are from, also considered under the present study even though it was found that there is no significant differences in preferred coaching style due to the impact of nationality in previous studies (Terry, 1984). Yet Sri Lanka is considered as a multicultural country and since this factor is yet not considered under Sri Lankan context, the present study used it as an influential factor for coach leadership styles.

The Coach Leadership Styles (CLS) specified in Leadership Scale for Sports (LSS) includes five styles specifically training and instruction behavior, democratic behavior, autocratic behavior, social support and positive feedback behavior (Chelladurai \& Saleh, 1980). LSS used as the instrument to support Celladurai's Multidimensional Model (MML) Chelladurai and Saleh (1980). Weiss and Friedrichs (1986), Alemu and Babu (2012), Pilus and Saadan, (2009), had utilized LSS questionnaire in their scholarly work. If a coach possesses training and instruction behavior, he would help athletes to acquire their extreme physical potential by provision of required training and technical support (Chelladurai, 2007). Autocratic style indicates that the coach keeps authority in decision making with him and stresses athletes when dealing with them and in contrast democratic style reflects the fact that the coach practices participative decision making process where athletes also considered as a part of it (Chelladurai, 2007; Calvo \& Topa, 2019). A coach who possesses social support behavior would involve in satisfying the interpersonal needs of the athletes/players. Verbal and visual compliments and reinforcements make by coach depicts his positive feedback behavior (Chelladurai, 2007; Kim \& Cruz, 2016).

There are different methods of accessing team success. Team success was operationally defined as the total winning percentage of a team for which games played in their regular competitive agenda. A percentage score will be calculated by dividing the number of points obtained by the maximum number of possible points (Carron, Bray, \& Eys, 2002; Perera \& Pushpakumari, 2016). A research conducted to examine the relationship between coach leadership, the athlete relationship, team success, and the positive development experiences of adolescent soccer players measured team success by the total number of competition points accumulated during a season (Vella, Oades, \& Crowe, 2012; Perera \& Pushpakumari, 2016; Perera, Jusoh, Azam, \& Sudasinghe, 2019; Perera, 2015; Abdullah, Musa, Maliki, Kosni, \& Suppiah, 2016).

The conceptual framework developed to the study is as follows.

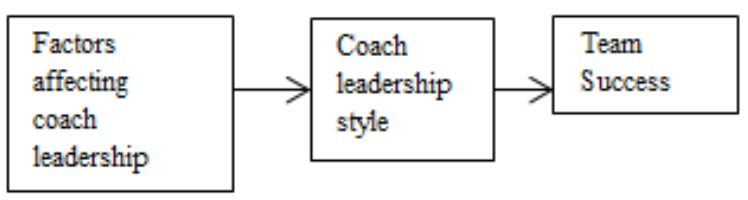

Figure 1. Conceptual Framework of the study

\section{Methodology and Data Analysis}

Participants completed The Revised Leadership Scale for Sports (RLSS) (Zhang, Jensen, \& Mann, 1997) and a self-developed questionnaire to measure team success. The population of the study was 160 team players from the teams representing Basketball, Volleyball, Field Hockey, and Elle, and the sample derived was also 160.

The questionnaire was pilot tested by directing it to a sample of 25 players. The reliability of the questionnaire was assessed using the Cronbach's Alpha test and the questionnaire was found to be acceptable with a Cronbach's Alpha value of 0.891. Nunnaly (1978) has indicated that a Cronbach's Alpha value of 0.7 is an acceptable reliability coefficient. The questionnaire was thereafter distributed among the total population under the supervision of the researcher in order to obtain relevant information for the study.

Correlations matrix for each coach leadership behavior style were developed and the values lied between 0.3 and 0.8 . Cohen uses a benchmark of minimum correlation value of 0.3 (Cohen.J, 1988), for convergent validity. The correlation coefficients reported in this study vary from 0.3 to 0.8 and hence considered to have discriminant validity also. The data collected were also subjected to Kaiser-Meyer-Olkin (KMO) and Bartlett test analyses to test the scale's structure validity, yielding to the results of KMO for training and instruction behavior 0.919, Democratic behavior 0.756, Social support behavior 0.751, positive feedback behavior 0.748 , and situational consideration behavior 0.745 . The Average Variance Extracted (AVE) was calculated to ascertain construct validity, and all the values were more than 0.5 . This elaborates that at least as much explained compared to unexplained.

Methods used to analyze data were General Linear model and Multiple Linear Regression. Multiple Linear Regression was conducted to analyze the relationship between factors affecting leader behavior styles and coach leadership behavior and coach leadership behavior styles 
and team success. Sobel's test was used to analyze the mediating effect of Coach Leadership behavior styles which depicts in Figure 2. Additionally, the results of direct and indirect effect of path coefficients also used to further prove the mediating effect.

A total of 160 subjects participated in the study. The descriptive statistics are as follows.

Table 1. Descriptive Statistics

\begin{tabular}{|c|c|c|}
\hline Variable & Frequency & Percentage \\
\hline Gender & & \\
\hline Male & 91 & $56.88 \%$ \\
\hline Female & 69 & $43.12 \%$ \\
\hline Age & & \\
\hline $20-22$ & 37 & $23.12 \%$ \\
\hline $23-25$ & 108 & $67.5 \%$ \\
\hline $26-28$ & 15 & $9.38 \%$ \\
\hline Living Area & & \\
\hline Urban & 45 & $28.12 \%$ \\
\hline Suburb & 54 & $33.75 \%$ \\
\hline Rural & 61 & $38.13 \%$ \\
\hline
\end{tabular}

According to Table 1, most of the participants were male $(56.88 \%)$ and females were $43.12 \%$. Age of team players ranged from 20 to 28 years. The age was categorized into three groups as $20-22$ years $(23.12 \%), 23-25(67.5 \%)$, and $26-28$ years $(9.38 \%)$. The living areas were categories into three groups (Table 2). As Table 1 illustrates, more participants are from rural area $(38.13 \%)$.

The impact of factors affecting coach leadership styles (FACLB) on coach leadership behavior (CLB) was also analyzed.

Table 2. The Relationship between Faclb and $\mathrm{Clb}$

\begin{tabular}{|c|c|}
\hline FACLB & Mean comparison \\
\hline Situational Factors & 3.30 \\
\hline Characteristics of the Coach & 3.58 \\
\hline $\begin{array}{c}\text { Team member } \\
\text { Characteristics }\end{array}$ & 3.63 \\
\hline
\end{tabular}

According to the mean figurers depicts in Table 2, it can be concluded that the above mentioned characteristics make impact on coach leadership behavior.

The impact of CLB on team success was also analyzed. According to Table 3, only training and instruction behavior is the significant predictor of team success which is measured through winning percentage.

The overall effect of coach leadership behavior (CLB) on team success was also analyzed and found that CLB is a significant predictor of team success $(\mathrm{p}=0.000)$.

Table 3. The Relationship between Coach Leadership Styles and Success

\begin{tabular}{|c|c|c|c|c|c|}
\hline \multirow{2}{*}{ Model } & \multicolumn{2}{|c|}{ Unstandardized Coefficients } & $\begin{array}{c}\text { Std. } \\
\text { Coeff }\end{array}$ & T & Sig. \\
\cline { 2 - 6 } & B & Std. Error & Beta & &. .129 \\
\hline Cons. & -.030 & .231 & & 9.53 & .897 \\
\hline TIB & .268 & .028 & .707 & -1.36 & .000 \\
\hline DB & -.042 & .031 & -.102 & -.787 & .174 \\
\hline AB & -.021 & .027 & -.054 & -.013 & .433 \\
\hline SSB & .000 & .028 & -.001 & -.587 & .990 \\
\hline PFB & -.031 & .052 & -.049 & -.377 & .558 \\
\hline SCB & -.022 & .058 & -.031 & 4.48 & .707 \\
\hline CLB & .270 & .060 & .336 & .000 \\
\hline
\end{tabular}

DV: Team Success 
According to Figure 2, the independent variable (IV) is Factors Affecting Coach leadership Behavior (FACLB), the mediating variable (MV) is Coach Leadership Behavior (CLB) and the dependent variable (DV) is Team Success. In Figure 2, "a" denotes the effect of FACLB on CLB, "b" denotes the effect of CLB and team success and similarly "c" represents the effect of FACLB on Team Success.

Mediation effect was first tested through generating path coefficients. The summary results of path coefficients estimates are as follows.

According to Table 4, the $p$ value resulting for FACLB,
CLB and team success is $0.000(\mathrm{p}<0.05)$ and therefore found that CLB mediates FACLB to team success relationship. FACLB to CLB is not significant since $\mathrm{p}$-value $=0.673$ which is more than 0.05 and hence not significant. Therefore it can be concluded that CLB is a total mediator between FACLB and team success.

The model used to analyze the mediation effect using path coefficient and Sobel's test depicts in Figure 2. The Sobel test is a statistical method of testing the significance of a mediation effect. The test is based on the work of Michael E. Sobel, (Sobel, 1982). (Sobel, 1982)

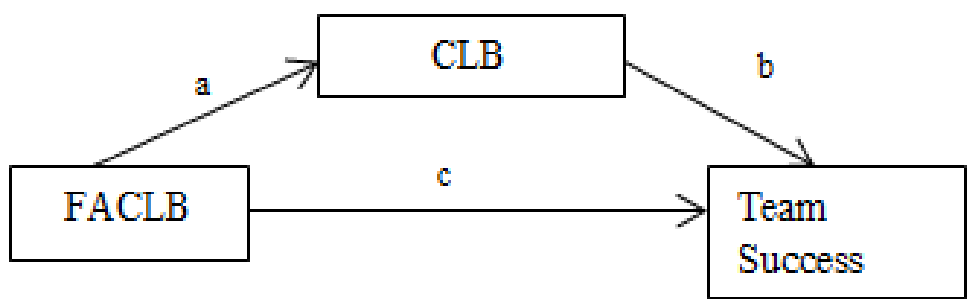

Figure 2. Mediation model

Table 4. Coefficient for Mediating Effect

\begin{tabular}{|c|c|c|c|c|c|}
\hline Testing Paths & $B$ & $S E(B)$ & $95 \% C I$ & $B$ & $\operatorname{Sr} 2$ \\
\hline \multicolumn{6}{|c|}{ Path $\mathrm{c}-\mathrm{DV}=$ winning/Team success } \\
\hline \multicolumn{6}{|c|}{$\mathrm{R}^{2}=0.113, \mathrm{~F}(1,160)=0.179, \mathrm{p}=0.673$} \\
\hline $\mathrm{IV}=\mathrm{FACLB}$ & 0.049 & 0.115 & $-0.179,0.276$ & 0.036 & $3.6 \%$ \\
\hline \multicolumn{6}{|c|}{ Path a; DV =Coach leadership style } \\
\hline \multicolumn{6}{|c|}{$\mathrm{R}^{2}=0.038, \mathrm{~F}(1,160)=6.16, \mathrm{p}=0.014$} \\
\hline $\mathrm{IV}=\mathrm{FACLB}$ & -0.418 & 0.169 & $-0.751,-0.085$ & -0.194 & $-19.4 \%$ \\
\hline \multicolumn{6}{|c|}{ Path b and c; DV; winning/Team success } \\
\hline \multicolumn{6}{|c|}{$\mathrm{R}^{2}=0.144, \mathrm{~F}(1,160)=11.263, \mathrm{p}=0.000$} \\
\hline $\mathrm{IV}=\mathrm{FACLB}$ & 0.168 & 0.110 & $-0.049-0.385$ & 0.125 & $12.2 \%$ \\
\hline $\mathrm{IV}=\mathrm{CLB}$ & 0.320 & 0.068 & $0.186-0.453$ & 0.388 & $37.8 \%$ \\
\hline Total & & & & -0.075272 & \\
\hline
\end{tabular}


Subsequently, Sobel's test (Sobel, 1982)was conducted. Values were substituted to the following Sobel's formula.

$$
\mathrm{z} \text {-value }=\mathrm{a} * \mathrm{~b} / \mathrm{SQRT}(\mathrm{b} 2 * \mathrm{sa} 2+\mathrm{a} 2 * \mathrm{sb} 2)
$$

The value derived by Sobel's Model was -1.12538014 . The $a b$ product is judged to be statistically significant if ' $z$ ' is greater than +1.96 or less than -1.96 . Because $z=-1.125$, with $\mathrm{p}=0.000$, two-tailed, the ab product that represents the effect of FACLB on team success mediated by CLB can be judged statistically significant.

\section{Discussion}

The primary intention of the study was to examine the relationship between factors affecting coach behavior and coach leadership styles. The results of the study revealed that there is moderate impact of situational factors, characteristics of coach and team member characteristics on coach leadership styles. The previous studies prove the factors dealt with coach (Leader characteristics) for instance coach's age level relate with coach behavior (Riemer \& Toon, 2001; Rintaugu, Bailasha, \& Toriola, 2011) are making influence on coach leadership behaviors which is consistent with the present study. According to the preset study, age level of the coach is affected to the coach leadership styles but less likely in case of Autocratic behavior which is partially consistent with the previous studies (Rintaugu, Bailasha, \& Toriola, 2011; Terry \& Howe, 1984). Furthermore it is found that there is moderating impact of said variables on Coach leadership behavior which is consistent with the previous studies conducted in Sri Lanka with a sample size of 291 athletes (Perera \& Pushpakumari, 2015; Perera \& Pushpakumari, 2015).

The findings of this research on relationship between coach leadership behavior and team success revealed that CLB is a significant predictor of team success and furthermore found that training and instruction behavior of coach as the most with the findings of Rintaugu and Bailasha (2011), Alemu \& Babu (2012), Vahdani et al (2012) and partially agree with Terry (1984) on preferences made by them on training behavior. But the results are not consistent with the research findings made by Bahrami et al (2011) and Donald, et.al (2019). The results of the study partially agreed with the findings of Perera \& Pushpakumari (2016), in relation to Sri Lanka Context.

A study conducted by Cruz and Kim (2017) indicated that young athletes strongly preferred training and instruction, followed by positive feedback, democratic behavior, social support, and autocratic behavior.

The main intention of the study was to evaluate the validity of the mediation model developed by Smith and Smoll in 1989. Accordingly, one of the objectives was derived to assess the mediating effect of CLB in the relationship between FACLB and team success. The results of this study provided strong support for the proposed model in which coach leadership behavior mediates the relationship between factors affecting coach leadership behavior and team success which was derived through path coefficient and Sobel's test.

\section{Conclusions}

This study, at the inception, examined the relationship between factors affecting coach behavior and coach leadership styles and found that these factors make an impact on coach leadership behavior. Mean of the scores was used to analyze the relationship between factors affecting leader behavior styles and coach leadership behavior and found that situational, coach and team member characteristics make impact on coach leadership behavior and at the same time the impact of CLB on team success was also analyzed using General Linear model and Multiple Linear Regression. The results concluded that training and instruction behavior is the only significant predictor of team success which is measured through winning percentage. The overall effect of CLB on team success was also analyzed and found that CLB is a significant predictor of team success. Path coefficient and Sobel's test was conducted to analyze the mediation effect of coach leadership behavior between FACLB and team success. Subsequently, it was found that FACLB on team success was mediated by CLB. Study Results further concluded that CLB is a total mediator between FACLB and team success. Furthermore the results obtained relating to above mentioned relationships found consistent with previous studies.

The implications of the study are depicted in the light of the findings of the study, and the following recommendations were forwarded. 1. A coach should promote training and instruction leadership style among his team because lots of team players urge and they perceive the said behavior of the coach which will lead to their success 2. Continuous studies comprising qualitative method of research should be done in the future to identify the other factors other than coach leadership style which will lead towards team success, 3 . The same study to be conducted before and after a competition (Pre and post) and analyze whether the players perceive the same said factor (training and instruction behavior) as the only predictor of team success.

\section{REFERENCES}

[1] Alemu, SM., Babu, MS. (2012) The relationship between coaches' team cohesion and team cohesion and team success: The case of premier league soccer clubs in Ethiopia. IRJC. 1, 1-13

[2] Abdullah, M., Musa, R., Maliki, A., Kosni, N., \& Suppiah, P. 
(2016). Role of psychological factors on the performance of elite soccer players. Journal of Physical Education and Sport, 16(1), 170-6.

[3] Calvo, C., \& Topa, G. (2019). Leadership and Motivational Climate: The Relationship with Objectives, Commitment, and Satisfaction in Base Soccer Players. Behav. Sci, 2-10.

[4] Biyanwila, B., \& Perera, H. (2018). Associated factors for efficient development of Scool sports system for National level sports in Sri Lanka. Basic and Applied Sciences. 11, p. 29. Colombo: General Sir John Kotelawala Defence University.

[5] Calvo, C., \& Topa, G. (2019). Leadership and Motivational Climate: The Relationship with Objectives, Commitment, and Satisfaction in Base Soccer Players. Behav. Sci, 2-10.

[6] Carron, A., Bray, S., \& Eys, m. (2002). Team cohesion and team success in sport. Journal of Sports Sciences, 20, 119-26.

[7] Chelladurai, P. (2007). Leadership in Sports. In G. Tenebaum, \& R. Eklund, Handbook Of Sport Psychology. New Jersey: John Wiley \& Sons.

[8] Chelladurai, P., \& Arnott, M. (1985). Decision Styles in Coaching: Preferences of Basketball Players. Research Quarterly for Exercise and Sport, 56(1), 1985.

[9] Chelladurai, P., \& Carron, A. (1983). Athletic Maturity and Preferred Leadership. Journal of Sport Psychology, 5(4), 371-80.

[10] Chelladurai, P., \& Saleh, S. (1980). Dimensions of Leader Behavior in Sports: Deveiopment of a Leadership Scaie. Journal of Sport Psychology, 2, 34-45.

[11] Chelladurai, P., \& Saleh, S. (1980). Dimensions of leader behavior in sports: development of a leadership scale. Journal of Sport Psychology, 2, 34-45.

[12] Cohen.J. (1988). J. Cohen, Statistical Power Analysis for the Behavioral Sciences, Erlbaum, NJ, USA, 2nd edition, 1988. (2nd ed.). Hillsdale, NJ, USA: Lawrence Erlbaum Associates, Inc., Publishers.

[13] Cruz, A., \& Kim, H. (2017). Leadership Preferences of Adolescent Players in Sport: Influence of Coach Gender. Journal of Sports Science and Medicine, 16, 172-179.

[14] De Bossche, V., De Knop, P., Bottenburg, M., \& Shibli, S. (2006). A conceptual framework for analysing sports policy factors leading to international sporting success. European Sport Management Quarterly, 6(2), 185-215.

[15] Donald, K., Marvin, S., Farmer, A., \& Cypress, K. (2019, July 19). The Association Between High School Coach's Leadership Behaviors and Athletes' Self-Efficacy and Grit. (K. Donald, Ed.) The Sport Journal.

[16] Gould, D., Greenleaf, C., Guinan, D., \& Chung, Y. (2002(b)). A Survey of U.S. Olympic Coaches: Variables Perceived to Have Influenced Athlete Performances and Coach Effectiveness. The Sport Psychologist, 16, 229-50.

[17] Greenleaf, C., Gould, D., \& Dieffenbach, K. (2001). Factors Influencing Olympic Performance: Interviews with Atlanta and Negano US Olympians. Journal of Applied Sport Psychology, 13(2), 154-84.
[18] Gunnarsson, I. (2017). Intrinsic motivation of college athletes and football players in Iceland:Effects of coaches' leadership style and determinants of intrinsic motivation. Retrieved January 18, 2018, from https://skemman.is/bitstr eam/1946/27701/1/Hj\%C3\%B6rtur-\%C3\%9E\%C3\%B3ris son.pdf

[19] Hays, K., Thomas, O., Maynard, I., \& Bawden, M. (2009, September). The role of confidence in world-class sport performance. Journal of Sports Sciences, 27(11), 1185-99..

[20] International olympic Committee. (2009). International olympic Committee (IOC). Retrieved February 10, 2018, from IOC web site: https://www.olympic.org/about-ioc-ins titution

[21] Kim, H., \& Cruz, B. (2016). The influence of coaches' leadership styles on athletes' satisfaction and team cohesion: A meta-analytic approach. International Journal of Sports Science \& Coaching, 11(6), 900-909.

[22] Nicholls, J. (1984). Achievement motivation: conceptions of ability, subjective experience, task choice, and performance. Psychol. Rev. Psychol. Rev(91), 328-46.

[23] Nyangahu, K., \& Bula, H. (2015, December 25). Relationship between Work Stress and Perfomance of Employees: A Case Study of Transit Hotel in Nairobi City Country. Archieves of Business Research, 3(6), 22-37.

[24] Ogiamien, L., \& Izuagbe, R. (2016). Impact of Organisational and Psychological Factors on the Job Performance of Personnel in Private University Libraries in South-South Nigeria. OALibJ, 3( e2419), 1-14.

[25] Perera, H. (2015). The relationship between coach leadership behaviorand team success in sports:An empirical study of state universities in Western Province. University of Sri Jayewardenepura.

[26] Perera, H., \& Pushpakumari, ,. M. (2016). The relationship between Coach Leadership Behavior and Team Success In sports of State universities In Western, Province Sri Lanka. iNCOTeM. 1, pp. 47-51. Colombo: Department of Management of Technology, University of Moratuwa, Katubedda.

[27] Perera, H., \& Pushpakumari, M. (2015). An empirical study of Situational, Leader and Team member characteristics on coach leadership behavior styles Exhibited by the coaches of state Universities in Western Province. International conference on Multidiciplinary Approaches-2015 (ICMA) (p. 158). Colombo: Faculty of Graduate studies, University Of Sri Jayewardenepura.

[28] Perera, H., \& Pushpakumari, M. (2015). the perception of Athletes on the Factors Affecting to Coach Leadership Behavior styles: An empirical study on leadership styles Exibited by the Coaches of State Universities in Western Province- Sri Lanka. International Journal of Multidisciplinary Studies (IJMS), 2(2), 83-91.

[29] Perera, H., Jusoh, M., Azam, S., \& Sudasinghe, S. (2019). Study of Intrinsic Motivation as a predictor of players' performance in Team Sports. International Journal of Advance Engineering and Research Development, 6(1), 155-157.

[30] Pilus, AHM, Saadan, R. Coaching Leadership Styles And 
Athletes Satisfaction Among Hockey Team. J Hum Capital, 2009; 2, 77-87

[31] Riemer, H., \& Toon, K. (2001). Leadership, Satisfaction in Tennis: Examination of Congruence, Gender \& Ability. Res Q Exercise Sports, 72, 243-56.

[32] Rintaugu, E., Bailasha, N., \& Toriola, A. (2011). Psycho-social attributes of elite African women volleyball players: Sport psychology. African Journal for Physical, Health Education, Recreation and Dance, 17(3), 535-546., 17(3), 535-46

[33] Rotter, J. (1966). Generalized expectancies for internal versus external control of reinforcement. Psychological Monographs , 80(1), 1-28.

[34] Saad, R., \& Asaad, M. (2014). DOES ORGANIZATIONAL CULTURE MODERATE THE RELATIONSHIP BETWEEN ISO 9000 SOFT FACTORS AND ORGANIZATIONAL PERFORMANCE? Proceedings of the Australian Academy of Business and Social Sciences Conference 2014. Journal of Developing Areas.

[35] Smoll, F., \& Smith, R. (1989). Leadership behaviors in sport: A theoretical model and research paradigm. Journal of Applied Social Psychology, 19, 1522-51.

[36] Smoll, F., \& Smith, R. (1989). Leadership Behaviors in Sport: A Theoretical Model and Research Paradigm. JournalofAppliedSocial Psychology, 19(18), 1522-51.

[37] Sobel, M. (1982). Asymptotic confidence intervals for indirect effects in structural equation models. In $\mathrm{S}$. Leinhardt, Sociological Methodology (pp. 290-312). Washington DC: American Sociological Association.

[38] Sofi, M., \& Devanadhen, K. (2015). Impact of Organizational Culture on Organizational Performance: an Empirical Assessment of Banking Sector in Jammu and Kashmir India. International Journal of Innovative Research \& Development, 4(9), 34-44.

[39] Terry, P. (1984, December 09). The coaching preferences of elite athletes competing at Universiade '83. Can J Appl Sport Sci, 9(4), 201-8.

[40] Terry, P., \& Howe, B. (1984). Coaching preferences of athletes. Can J Appl Sport Sci, 9(4), 188-93.

[41] Totterdell, P. (2000). Catching Moods and Hitting Runs: Mood Linkage and Subjective Performance in Professional Sport Teams. Journal of Applied Psychology, 85(6), 848-59.

[42] UN Inter-Agency task Force on Sports for Development and Peace. (2005). Sports as a Tool for Development and Peace: Towards Achieving the United Nations Millennium Development Goals. UN.

[43] Vella, S., Oades, T., \& Crowe, T. (2012). The relationship between coach leadership, the coach-athlete relationship, team success, and the positive developmental experiences of adolescent soccer players. Physical Education and Sport Pedagogy, 18, 549-61.

[44] Weinberg, R., Tenenbaum, G., McKenzie, A., Jackson, S., Anshel, M., Grove, R., et al. (2000). Motivation for Youth Participation in Sport and Physical Activity: Relationships to Culture, Self-Reported Activity Levels, and Gender. Int.\} Sport Psychol, 31, 321-46.
[45] Weiss, MR., Fredrichs, WD. (1986).The influence of leader behaviors, coach attributes, and institutional variables on performance and satisfaction of collegiate basketball teams. J Sport Psychol, 332-46.

[46] Zhang, J., Jensen, B., \& Mann, B. (1997). Modification and Revision of the Leadership Scale for Sports. Journal of Sports Behavior, 20, 105-22. 